\title{
A Cost-effective, Miniature Electrical Ultrafine Particle Sizer (mini-eUPS) for Ultrafine Particle (UFP) Monitoring Network
}

\author{
Qiaoling Liu ${ }^{1 \#}$, Di Liu ${ }^{1 \#, ~ X i a o t o n g ~ C h e n ~}{ }^{1,2}$, Qiang Zhang², Jingkun Jiang², Da-Ren Chen ${ }^{1,2 *}$ \\ ${ }^{1}$ Particle laboratory, Department of Mechanical and Nuclear Engineering, Virginia Commonwealth University, \\ Richmond, VA 23284, USA \\ ${ }^{2}$ Division of Air Pollution Control, School of Environment, Tsinghua University, Beijing 100084, China
}

\begin{abstract}
A cost-effective, miniature electrical ultrafine particle sizer (mini-eUPS) has been developed for future UFP (ultrafine particle) monitoring networks in cities with high traffic density and in communities close to freeways, airports or stationary combustion sources. The mini-eUPS mainly consists of a mini-plate unipolar particle charger, a mini-plate differential mobility classifier and a mini-particle Faraday cage with a sensitive electrometer. A custom-made circuit board was designed for operating the mini-eUPS. In addition to the primary function of measuring the UFP size distribution, the mini-eUPS records the temperature, relative humidity, pressure, altitude, timing and location for each measured data set. The operational status of the mini-eUPS is also registered for data quality assurance. Due to the built-in features of selfdiagnosis, malfunction reporting and wireless networking, this particle sizer is suitable for UFP monitoring network. The prototype, which possesses overall dimensions of $6.5^{\prime \prime}(\mathrm{L}) \times 5.0^{\prime \prime}(\mathrm{W}) \times 4^{\prime \prime}(\mathrm{H})$ and a total weight of $\sim 1.0 \mathrm{~kg}$, measures particles ranging in size from 5 to $200 \mathrm{~nm}$. To evaluate the performance of the mini-eUPS, size distribution measurements of lab-generated particles in both unimodal and bimodal distributions and of UFPs emitted from a low-cost 3D printer and diesel engine were compared with those taken by a Scanning Mobility Particle Sizer (SMPS; TSI Inc.). A reasonably good agreement between the mini-eUPS and SMPS data was found.
\end{abstract}

Keywords: Miniature particle sizer; Ultrafine particles; Cost-effective sensor.

\section{INTRODUCTION}

The concern of adverse impact of ultrafine particles (UFPs, defined as particles in the sizes less than $100 \mathrm{~nm}$ ) on the environment and health has been increasing in recent years as the number of scientific evidences published in the literature increased. From the toxicological and health perspective, UFPs, due to their high surface-to-volume ratio and high number concentration, often possess high bio-availability and toxicity ( $\mathrm{Nel}$ et al., 2006; Heinlaan et al., 2008; Park et al., 2011). Peer-reviewed literature reports that UFPs could easily enter the human lung and deposit in the alveolar region, even entering in the blood stream and transporting to vital organs (Paur et al., 2001; Takenaka et al., 2001; Kreyling et al., 2002; Oberdörster et al., 2004). \footnotetext{
of this paper.

* Corresponding author.

E-mail address: dchen3@vcu.edu
}

${ }^{\text {\# }}$ Both Q. Liu and D. Liu have equal contribution to the work presented in this paper. They share the first-authorship
Epidemiologic studies have also shown that UFPs are particularly relevant to pulmonary diseases, cancer and mortality because of their high diffusion coefficient and greater accumulation ability (Delfino et al., 2005; Samet et al., 2007; Hoek et al., 2010; Steward et al., 2010; Ostro et al., 2015; Aguilera et al., 2016; Du et al., 2016; Heusinkveld et al., 2016; Li et al., 2017). The increased asthma prevalence has been often found to occur in the areas having high UFP level in the ambient or high motor vehicle traffic density and residence communities in close proximity to freeways (Samet et al., 2000; Holguin, 2008; Salam et al., 2008; Patel and Miller, 2009; Mazaheri et al., 2014; Dirks et al., 2016). In spite of the published health data, a causal relationship between the short-term UFP exposure and cardiovascular effects was suggestive, but not sufficient, by EPA 2009 PM Integrated Science Assessment, ISA (U.S. EPA, 2009; Baldauf et al., 2016). Limited data on the spatial/temporal variability in UPF concentration and on the UFP composition, and incomplete information on the spatial/temporal evolution of UPF size distribution are some of the limitations on the published health studies for the above causality determination.

UFPs are either derived directly from combustion and vehicle emission or formed when organic compounds with 
low vapor pressure spontaneously nucleate/condense on other small particles (Kulmala et al., 2004). UFPs are major sources for fine particles produced through the agglomeration and/or vapor condensation. In addition to their omnipresent existence in the ambient environment, UFPs of various chemical compositions have been manufactured for industrial applications. Example applications of industrial UFPs are silver nanoparticles in apparel for their antibacterial and anti-odor properties, the use of titanium dioxide and zinc oxide nanoparticles in cosmetics to effectively block the UV rays in the sunlight, and the inclusion of carbon nanoparticles in rubbers to lengthen the lifetime of vehicle tires (Lee et al., 2007; Vassiliou et al., 2008; Somasundaran et al., 2010; Madani et al., 2011; Smijs and Pavel, 2011).

However, the monitoring of ultrafine particles is challenging because of the rapid variation of size and concentration of UFPs both in time and in the distance from their sources, especially for the communities in close proximity to freeways/airports or in cities where a high density of motor vehicles are present (Zhu et al., 2002; Karner et al., 2010; Padró-Martínez et al., 2012; Patton et al., 2014; Manigrasso et al., 2017; Hudda et al., 2018). UFP monitoring networks in the resolution of 10-20 meters are required to collect the data needed for epidemiologic studies (Zhu et al., 2002). Establishing a UFP monitoring network thus requires multiple monitors as the network nodes. Scientific instruments for the UFP characterization have been developed and applied in various aerosol particle studies for decades. The review of instruments capable of measuring UFPs could be found in the literature (Chen and Pui, 2008). Instruments for the integral measurement of UFPs (i.e., total number, surface area and mass concentrations of UFPs) are available in market. Examples of integral instruments are condensation particle counters (CPCs), for total number concentration measurement; nanoparticle surface area monitors (NSAMs), for sensing total surface area concentration of particles deposited in a human lung; and electrical aerosol detectors (EADs), for measuring the total mass concentration of UFPs. In addition, particleelectrical-mobility-based instruments (e.g., Electrical Aerosol Analyzer, EAA, and Differential Mobility Analyzer, DMA) have been widely applied in measuring the size distributions of UFPs. Electrical-mobility-based instruments in the portable version (listed in the Table 1) have also been made available in recent years. The above UFP sizers are mainly designed for laboratory use and operated alone. They are typically expensive in list price and bulky/heavy in final packages, limiting the application in the UFP monitoring network. Cost-effective UFP sizers in much more compact packages are highly in demand for setting up a UFP monitoring network.

In this article, we report our effort in the development of a cost-effective, miniature electrical ultrafine particle sizer (mini-eUPS). Electrical-mobility-based techniques are the backbone of this mini-eUPS because of their capability of measuring the size distribution of UFPs. A typical electricalmobility-based particle sizer consists of a particle charger which imposes a well-defined charge distribution on particles to be measured, an electrical-mobility classifier which either sizes particles or changes size distribution of particles based on their electrical mobility, and a particle concentration detector which measures the concentration of particles being sized/changed. Typical particle concentration detectors are either CPCs or aerosol electrometers. In the following sections, we describe the configuration of mini-eUPS and its core components. The evaluation of core components and additional features of the mini-eUPS are also discussed. Examples are at last given to demonstrate the overall performance of the mini-eUPS.

\section{MATERIALS AND METHODS}

\section{Design of mini-eUPS and its Core Components}

Shown in Fig. 1 is the schematics of miniature electrical ultrafine particle sizer (mini-eUPS). The mini-eUPS consists of three core components: a unipolar mini-plate particle charger, a mini-plate differential mobility classifier, and a mini-particle Faraday cage with a sensitive electrometer. Ambient particles are sampled into the mini-eUPS via a miniature cyclone, to remove particles with the sizes larger than $200 \mathrm{~nm}$. Prior to entering the mini-plate charger, the temperature and relative humidity of the particle stream are measured. The used mini-cyclone was designed and calibrated according to the works of Hsiao et al. (2009) and Liu et al. (2015).

Table 1. Summary of compact/portable ultrafine particle sizers which are commercially available. The prototype mini-eUPS is listed herein for the comparison only.

\begin{tabular}{|c|c|c|}
\hline Instrument & Dimensions & Weight \\
\hline TSI Nanoscan 3910 & $\begin{array}{l}45 \times 23 \times 39(\mathrm{~cm}) \\
\left(18^{\prime \prime} \times 9^{\prime \prime} \times 15.3^{\prime \prime}\right)\end{array}$ & $\begin{array}{l}\sim 8 \mathrm{~kg} \text { (w/o batteries); } \\
\sim 9 \mathrm{~kg} \text { (with batteries) }\end{array}$ \\
\hline Kanomax portable aerosol mobility spectrometer (PAMS) & $\begin{array}{l}23 \times 23 \times 15(\mathrm{~cm}) \\
\left(9^{\prime \prime} \times 9^{\prime \prime} \times 6^{\prime \prime}\right)\end{array}$ & $4.5 \mathrm{~kg}$ \\
\hline Naneum Nano-ID PMC500 & $\begin{array}{l}30 \times 33 \times 26(\mathrm{~cm}) \\
\left.11.8^{\prime \prime} \times 13^{\prime \prime} \times 10.2^{\prime \prime}\right)\end{array}$ & $6.25 \mathrm{~kg}$ \\
\hline Grimm mini wide range aerosol spectrometer (WARS) & $\begin{array}{l}34 \times 31 \times 12(\mathrm{~cm}) \\
\left(13.4^{\prime \prime} \times 12.2^{\prime \prime} \times 4.7^{\prime \prime}\right)\end{array}$ & $7.6 \mathrm{~kg}$ \\
\hline miniature electrical ultrafine particle sizer (mini-eUPS) ${ }^{*}$ & $\begin{array}{l}16.5 \times 12.7 \times 10(\mathrm{~cm}) \\
\left(6.5^{\prime \prime} \times 5.0^{\prime \prime} \times 4^{\prime \prime}\right)\end{array}$ & $\sim 1 \mathrm{~kg}$ (w/o battery) \\
\hline
\end{tabular}

${ }^{*}$ it is listed for the comparison only (not commercially available). 


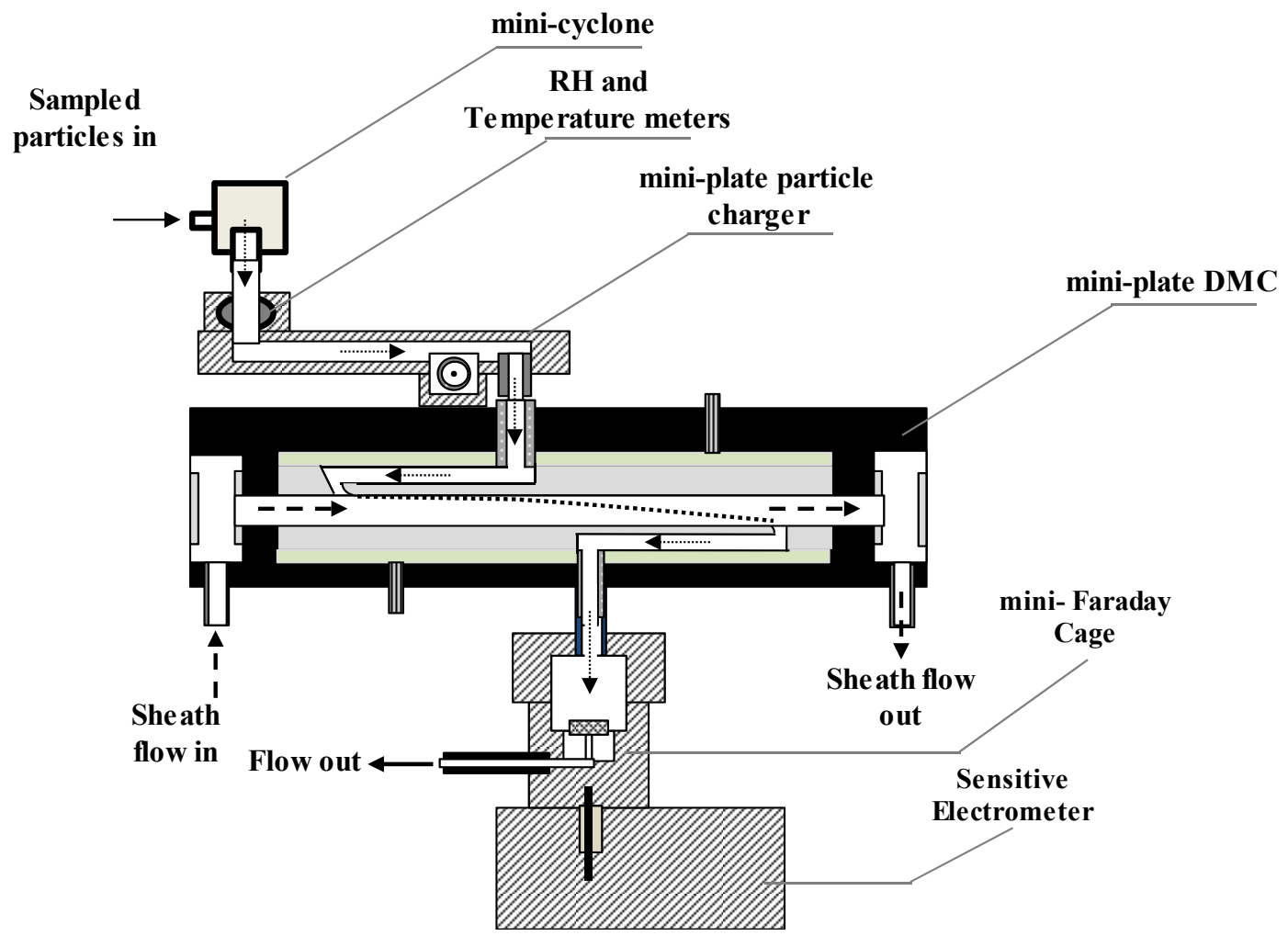

Fig. 1. Schematics of assembled miniature electrical ultrafine particle sizers (mini-eUPS).

After taking the temperature and relative humidity measurement, the particle stream is directed to a mini-plate unipolar charger (shown in Fig. 2(a)) to electrically charged particles (Liu, 2015; Chen et al., 2018). The charger is the modified version of the mini-plate particle charger studied in the dissertation work of Liu (2015), in which the detail optimization and performance evaluation of the mini-plate charger can be found. The particle charger included in the mini-eUPS is constructed by sandwiching one metal plate and one metal block. The particle flow channel (in the rectangular cross-section and with the tapered expansion inlet and contraction outlet) is embedded in the metal block with the inlet tube. The metal plate with the outlet tube is used as the channel cover for the flow channel. The ion generation chamber is located near the flow channel exit and built in the metal block. A perforated plate is used to partition the ion chamber from the flow channel. The particle-charging zone is defined in the channel space adjacent to the perforated plate. In the ion generation chamber, a Tungsten wire of $50 \mu \mathrm{m}$ in diameter is installed in the direction perpendicular to the flow for producing unipolar ions via positive DC-corona discharging. Once produced, a small portion of unipolar ions is diffused into the particle-charging zone. Particles enter the charger from the left inlet tube, pass through the particle charging zone where they acquire electrical charges by the random collision with unipolar ions, and exit the charger via the bottom outlet tube. The corona discharge is operated at $2.0 \mu \mathrm{A}$ in order to achieve the optimal performance of the charger. For the simplicity, no ion-driving voltage is applied in the operation of this charger. Note that an additional feature of sheath flow is also designed in the charger, offering a clean flow to reduce the possible contamination of corona wire.

A mini-plate differential mobility classifier (mini-plate DMC; shown in Fig. 2(b)) is placed at the exit of the miniplate particle charger to size particles according to their electrical mobility (Liu and Chen, 2016). The mini-plate $\mathrm{DMC}$ is in general constructed by two metal plates installed in parallel and separated by the spacing of $1.6 \mathrm{~mm}$ (i.e., $1 / 16^{\prime \prime}$, the height of particle classification zone). An aerosol flow contraction/expansion channel (for transporting either polydisperse or classified particles) is designed in each metal plate to minimize the electrostatic loss of charged particles. Polydisperse charged particles flow in the miniplate DMC from the top tube, through a flow expansion channel, to the particle classification zone via the entrance slit. The dimensions of aerosol entrance and exit slits are $28.6 \mathrm{~mm}$ (i.e., $11 / 8^{\prime \prime}$ in length), which is $\sim 75 \%$ of the full width of the classification zone. The reason for the reduced slit length (compared with the full channel width) is to minimize the wall effect on the DMC performance. The distance between the aerosol entrance and exit slits, i.e., the particle classification length, is $52.4 \mathrm{~mm}$ (i.e., 2 1/16"). Classified particles are extracted out the classification zone from the exit slit, moved through a flow contraction channel, and exited the DMC from the bottom tube. Particle-free sheath gas is directed into the particle classification zone via the left inlet and a flow laminarizor. The excess flow exits the classification zone from the outlet located on the other end of the DMC. A high DC voltage is applied to the top plate while the bottom one is on the electrical ground, 


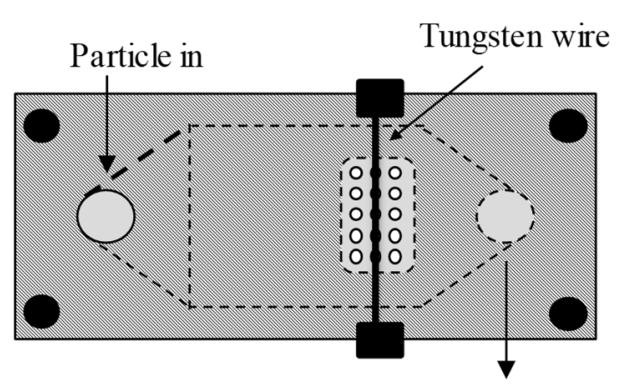

Particle out

Top View

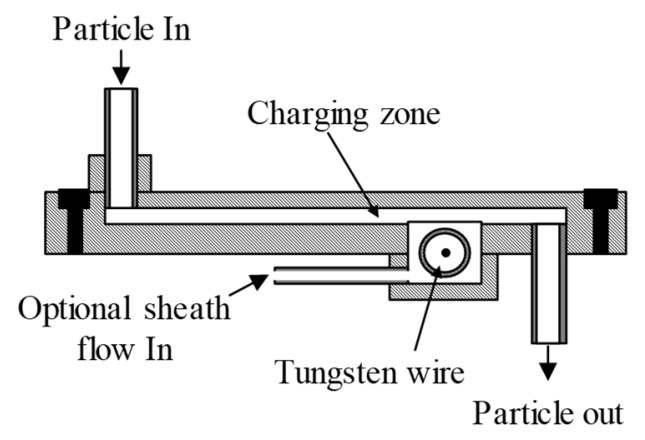

Side View

(a)

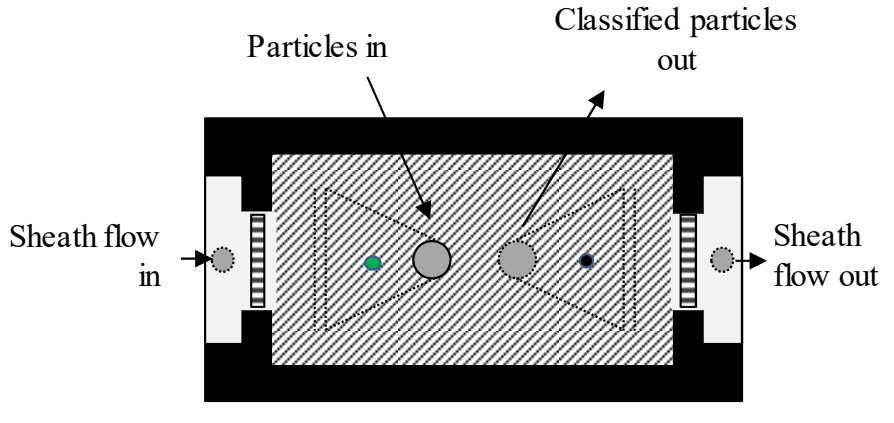

Top View

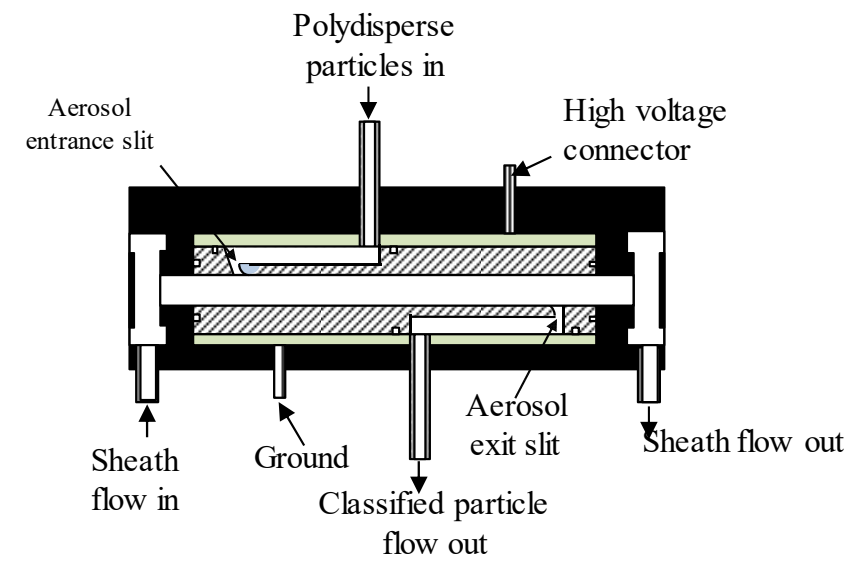

Side View

(b)

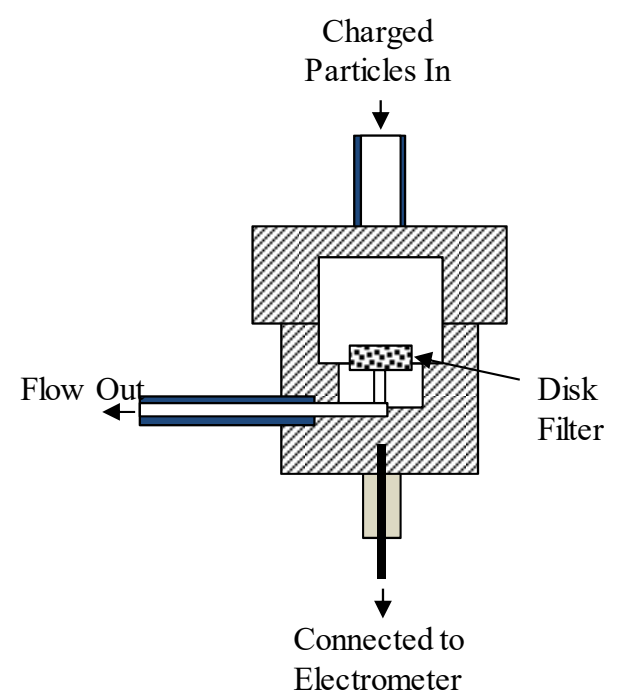

(c)

Fig. 2. Schematics of core components used in mini-eUPS: (a) mini-plate unipolar particle charger; (b) mini-plate differential classifier and (c) mini-particle Faraday cage.

establishing a uniform electrical field in the particle classification zone. For safety, the metal plates are electrically insulated. The overall size of this prototype mini-plate DMC is comparable to the size of an iPhone 6. Instead of the flowrate ratio of 1:10, the mini-plate DMC is in default operated at the aerosol and sheath flowrates of 0.3 and
1.5 $\mathrm{L} \mathrm{min}^{-1}$ (i.e., the flowrate ratio of 1:5) in the mini-eUPS.

Instead of condensation particle counters (CPCs), a mini-particle Faraday cage integrated with a sensitive electrometer is applied in the mini-eUPS for measuring the electrical charges of classified particles. The selection of an aerosol Faraday cage over a CPC is based on the 
consideration of energy consumption, working fluid handling, miniaturization and the cost of CPCs. Heating and cooling of the working fluid are required in a CPC to enlarge the sizes of classified particles for optically counting. These thermal processes consume much energy. Extra accessary is also required to accomplish the tasks of feeding, storage and refilling for the working fluid in a CPC. The extra accessary will increase the cost and package size of the mini-eUPS. Notice that the trade-off for using a particle Faraday cage over a CPC is the low detection limit of particle concentration. A $\mathrm{CPC}$ would measure the particle in the number concentration down to $1 \mathrm{\#} \mathrm{cm}^{-3}$. Particles in the number concentration more than $300 \mathrm{\#} \mathrm{cm}^{-3}$ for each size bin (when operated at the flowrate of $0.6 \mathrm{~L} \mathrm{~min}^{-1}$ ) is required for sensing via a particle Faraday cage, because of the lower detection limit of $0.5 \mathrm{fA}$ of the current electrometer. Although the low current limit will be reduced to $0.2 \mathrm{fA}$ in the later version of electrometer to be incorporated in the mini-eUPS, classified particles in the concentration more than $100 \mathrm{\#} \mathrm{cm}^{-3}$ for each size bin are required for concentration sensing (assuming unit charge on individual classified particles).

Fig. 2(c) shows the schematics of mini-particle Faraday cage used in mini-eUPS. Charged particles are directed into the cage through the top inlet tube, and trapped in a small disk filter located in the metal cup which is electrically isolated from the cage and grounded through a wire. A sensitive electrometer connected to the wire is used in order to measure the induced current once the charged particles are trapped. After passing through the disk filter, the carry flow exits the cage from the outlet tube.

\section{Integration of mini-eUPS}

Two small high-voltage power supplies (EMCO C50 and Q50-5) are included in the mini-eUPS for the operations of the unipolar mini-plate particle charger and mini-plate DMC. For the charger operation, a feedback control loop is designed to keep the corona discharge current constant (at the default setting of $2.0 \mu \mathrm{A}$ ). One small air pump (135 FZ, Schwarzer Precision) and a micro-bridge flow meter (AWM43600V, Honeywell) are used to sample and monitor particle flows, respectively. For the mini-plate DMC operation, the second small pump (140 FZ, Schwarzer Precision) is applied as the driver to extract the excess flow for its port, pass it through two HEPA-grade tube filters (located at the upstream and downstream of the pump), and inject it into the sheath flow port. The second micro-bridge flow meter (AWM3300V, Honeywell) is used to monitor the circulating flow rate.

A custom-made circuit board and an A/D card were used to acquire the readings from high-voltage supplies, micro-bridge flow meters, and temperature and humidity sensors, and to control high-voltage power supplies and air pumps. In addition, the wireless communication and networking modules, timer, Global Positioning System (GPS) and pressure sensor are also included in the same circuit board. The Raspberry Pi micro-processor with the 7" touch screen is selected as the user interface, and for running the code for the mini-eUPS operation and data analysis/display.

The prototype mini-eUPS is in default operated at the stepping voltage mode in order to simplify the coding. The scanning voltage operation mode will be later included in the code. As the default setting, 20 size bins covering the sizes ranging from 5 to $200 \mathrm{~nm}$ are set in the mini-eUPS. Because of the response time of electrometer varies at different current levels, the measuring cycle is set at 60 seconds (i.e., 3 seconds for each size bin on average). The measuring cycle could be reduced when measuring UFPs in high concentration. It is because of the fast response time of electrometer at the high readout compared with that at the low signal.

The assembled mini-eUPS with all the accessary is packed in the commercially available box having the size of $6.5^{\prime \prime}(\mathrm{L}) \times 5.0^{\prime \prime}(\mathrm{W}) \times 4^{\prime \prime}(\mathrm{H})$ and with the total weight of $\sim 1.0 \mathrm{~kg}$ (without the battery). Note that the package size could be further reduced if it was custom-made. Either a lithium-ion battery or an AC-to-DC power adapter can power the mini-eUPS. Two USB ports are also available for the communication between the mini-eUPS microprocessor and a laptop computer. For the reference, the design specification of mini-eUPS is summarized in Table 2.

To retrieve the particle size distribution from measured raw data, a data inversion scheme is required for mini-eUPS because of the presence of multiple charges on particles of the same size after passing through the particle charger. Mathematical techniques have been proposed for the data inversion (Kandlikar and Ramachandranst, 1999). The choice of a particular algorithm for the size distribution retrieval is always a trade-off among the algorithmic complexity, accuracy of reconstruction and available calculation power (Voutilainen et al., 2000). Under the consideration of limited computational power and memory available, we selected the constrained least-square method for the near in-situ screening of ultrafine particle size distributions measured. The constrained least-square scheme

Table 2. Summary of design specification of key components and prototype mini-eUPS.

\begin{tabular}{ll}
\hline \multicolumn{2}{c}{ Specification of prototype mini-eUPS } \\
\hline Final package & $6.5^{\prime \prime}(\mathrm{L}) \times 5.0^{\prime \prime}(\mathrm{W}) \times 4^{\prime \prime}(\mathrm{H})^{\mathrm{a}}$ \\
Dimensions & $\sim 1.0 \mathrm{~kg}($ w/o battery $)$ \\
Weight & $0.2 \mu \mathrm{A}$ \\
mini-plate particle charger & \\
discharge current & $2-5 \mathrm{kV}$ \\
voltage range & $0.3-0.6 \mathrm{~L} \mathrm{~min}{ }^{-1}$ \\
flow rate & $0.3-0.6 \mathrm{~L} \mathrm{~min}^{-1}$ \\
mini-plate differential mobility classifier \\
particle flow rate & $1.5-3.0 \mathrm{~L} \mathrm{~min}^{-1}$ \\
sheath flowrate & $0-5 \mathrm{kV}$ \\
voltage range & $5-200 \mathrm{~nm} \mathrm{at} 1.5 \mathrm{~L} \mathrm{~min}^{-1}$ \\
particle size range & \\
mini-particle Faraday cage & \\
lower current limit & $0.5 \mathrm{fA}^{\mathrm{b}}$ \\
particle flow rate & $0.3-0.6 \mathrm{~L} \mathrm{~min}^{-1}$ \\
\hline
\end{tabular}

${ }^{*}$ for the prototype mini-eUPS only (subject to change).

${ }^{a}$ commercially available box.

b $\sim 300 \mathrm{\#} \mathrm{cm}^{-3}$ (singly-charged particles) at $0.6 \mathrm{~L} \mathrm{~min}^{-1}$. The detection limit would be $\sim 0.2 \mathrm{fA}$ in the near future. 
was first developed by Philips (1962) and later introduced into the aerosol measurement by Twomey $(1965,1975)$. For retrieving agreeable size distribution, the constrained method, with a maximum error tolerance of $5 \%$ in the measurements was reported by Rizzi et al. (1982) and Markowski (1987). Please note that the built-in data inversion is only for the quality screening of measured data. The final size distribution of UFPs could be obtained by offline data inversion schemes if the on-board data inversion was unsatisfactory (Wolfenbarger and Seinfeld, 1990; Talukdar and Swihart, 2003; Dubey and Dhaniyala, 2013).

\section{RESULT AND DISCUSSION}

\section{Core Components of mini-eUPS}

Prior to the mini-eUPS integration, the performances of core components were individually evaluated. The calibration method and detail performance of mini-plate DMC used in mini-eUPS could be found in the work of Liu and Chen (2016). The performance of the mini-plate particle charger and the mini- particle Faraday cage are given in this section.

The calibration of mini-plate particle charger was performed by the experimental setup and method detailed in the work of Chen et al. (2018). Fig. 3 shows the basic performance of mini-plate unipolar particle charger, i.e., intrinsic and extrinsic charging efficiencies as a function of particle size, when it was operated at the $2 \mu \mathrm{A}$ corona current and at the flow rate of $0.6 \mathrm{~L} \mathrm{~min}{ }^{-1}$. The intrinsic charging efficiency is defined as the percentage of particles receiving electrical charges in a particle charger and the extrinsic charging efficiency is the percentage of charged particles existing in a charger. The difference between the intrinsic and extrinsic efficiency is due to the particle loss in a charger. The charging efficiency of the charger increased as the particle size became larger. The extrinsic charging efficiency of $10 \mathrm{~nm}$ particles was about $12 \%$, evidencing a good charging performance of the mini-plate charger. For particles in sizes larger than $100 \mathrm{~nm}$, the intrinsic charging efficiency reached the maximal value of
$100 \%$ while the extrinsic charging efficiency stays $\sim 85 \%$. Also, the ratio of extrinsic charging efficiency to intrinsic charging efficiency increased with the increase of particle size, from $38 \%$ (for $20 \mathrm{~nm}$ particles) to $78 \%$ (for $60 \mathrm{~nm}$ particles), indicating that smaller particles were more likely lost in the charger. For the inversion scheme to retrieve the size distribution of UFPs, the charge distributions of particles at various sizes are also required. The charge distributions of particles in given sizes, which is required for the data inversion scheme applied in the mini-eUPS, were also measured and shown in Fig. 4. To reproduce measured charge distribution for particles in different size a Gaussian distribution function was proposed to fit the measured charge distribution data. It is found that the three parameters in the Gaussian distribution equation are functions of average charge and particle size. By best fitting the experimental charge distributions, a data-fitted Gaussian distribution equation for calculating the extrinsic charge distribution of particles can be expressed as:

$$
y=8.3691 D_{P}^{-0.655} \times \exp \left\{\frac{\left[x-\left(0.0281 D_{p}-0.1847\right)\right]^{2}}{\left(0.0039 D_{p}+0.5502\right)^{2}}\right\}
$$

where $D_{p}$ is particle size (unit: nm). As shown in Fig. 4, the general trend of the experimental and fitted charge distribution agrees well.

The performance of the mini- particle Faraday cage was calibrated, and the data are shown in Fig. 5. DMA-classified particles of $80 \mathrm{~nm}$ in diameter were used in the calibration of the mini- particle Faraday cage. The calibration was performed at both aerosol flow rates of 0.3 and $1.5 \mathrm{~L} \mathrm{~min}^{-1}$. The current (I) measured by the aerosol electrometer can be expressed as

$\mathrm{I}=\operatorname{ne}\left(\mathrm{NQ}_{\mathrm{a}}\right)$

where I is the current measured by mini- particle Faraday cage, $\mathrm{N}$ is the number concentration of single-charged

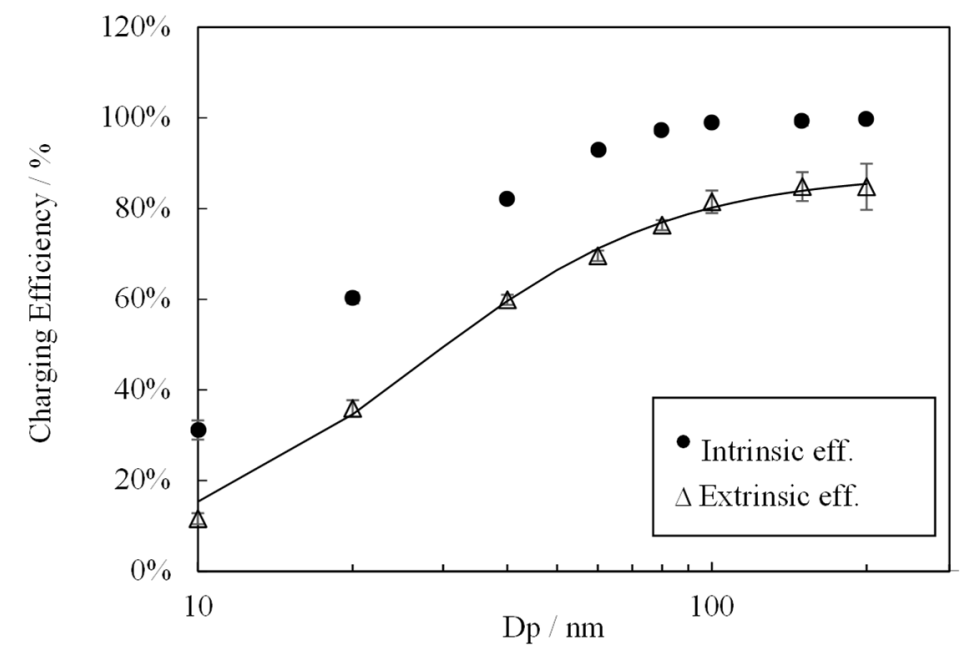

Fig. 3. Intrinsic and extrinsic charging efficiency of mini-plate unipolar particle charger as a function of particle size. 

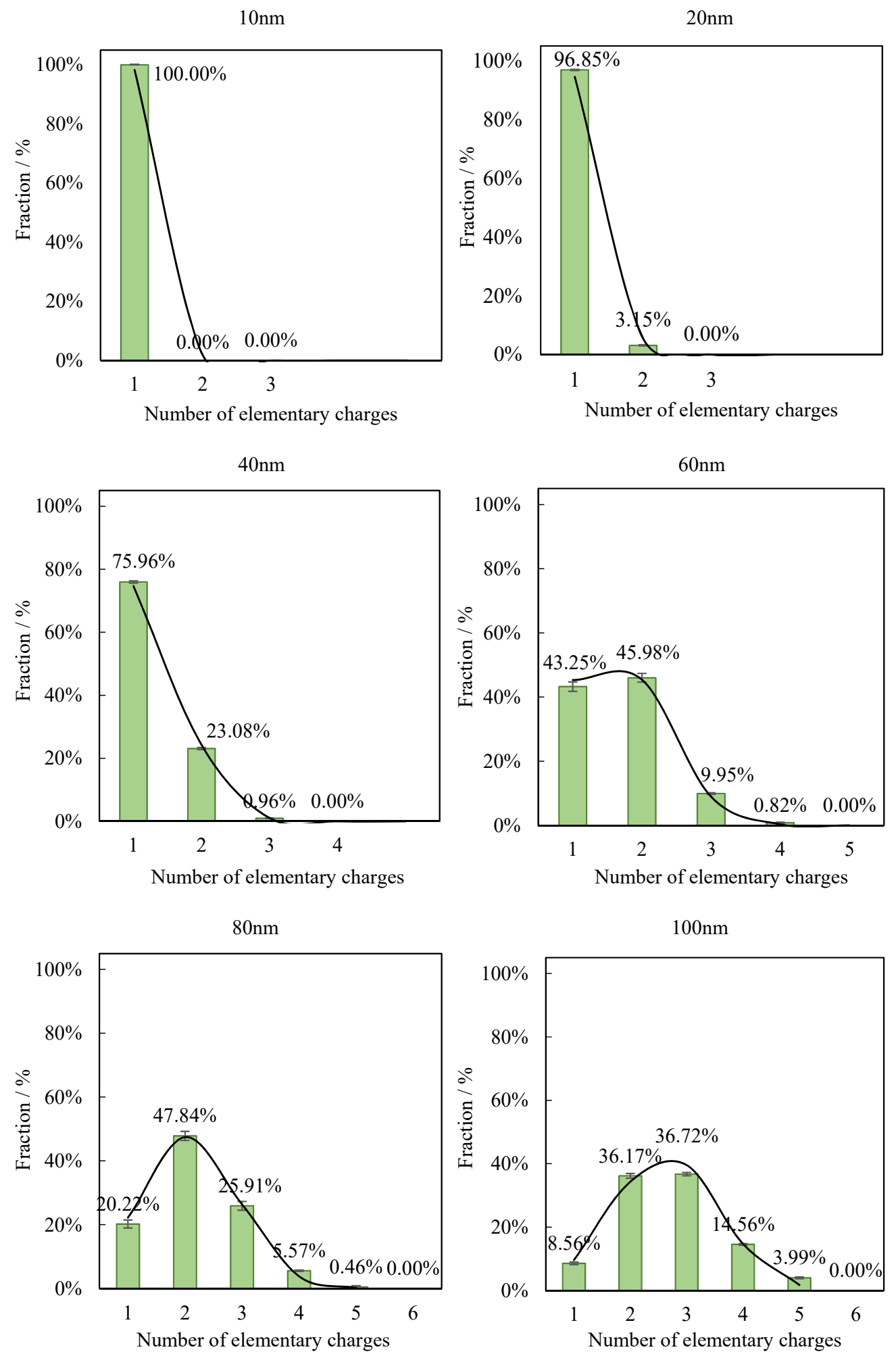

Fig. 4. Measured positive charge distributions of DMA-classified particles with various sizes when the mini-plate charger was operated at $0.6 \mathrm{~L} \mathrm{~min}^{-1}$ aerosol flowrate and $2 \mu \mathrm{A}$ corona current.

particles, measured by an Ultrafine Condensation Particle Counter (UCPC; Model 3776, TSI Inc.); $\mathrm{Q}_{\mathrm{a}}$ is the flow rate of particle stream, $\mathrm{n}$ is the number of elementary charges on individual particles ( $\mathrm{n}=1$ in this case), and $\mathrm{e}$ is the elementary charge $\left(1.6 \times 10^{-19} \mathrm{C}\right)$. Accordingly, the correlation between the measured current I and the $\mathrm{eNQ}_{\mathrm{a}}$ should be a straight reference line with the slope of 1.0 (or the $45^{\circ}$ in the plot). The excellent linear relationship between I and $\mathrm{eNQ}_{\mathrm{a}}$ is shown in Fig. 5 and the slopes of two lines are close to 1 (since all the test particles carried single charge). 


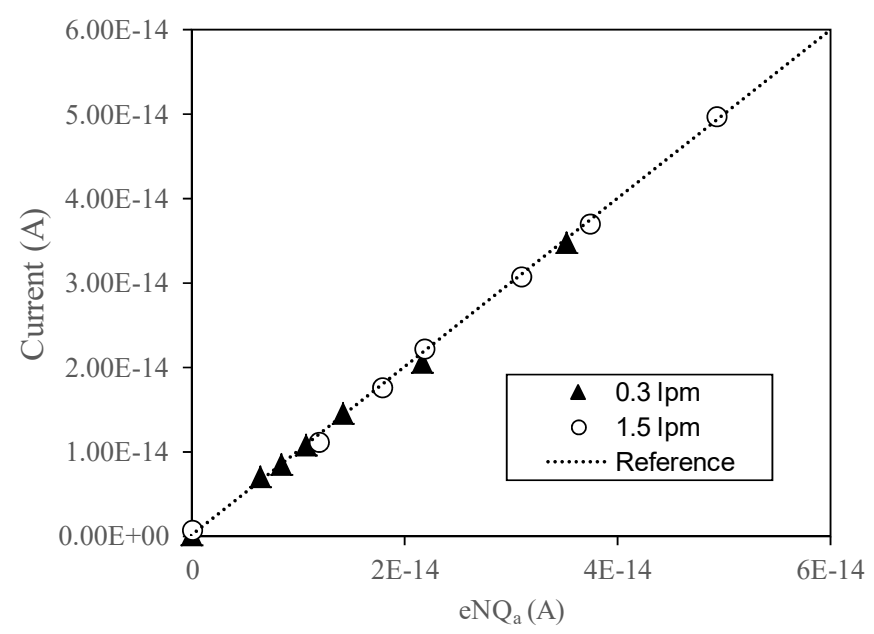

Fig. 5. Calibration curves of mini-particle Faraday cage at the flow rates of 0.3 and $1.5 \mathrm{~L} \mathrm{~min}^{-1}$.

\section{Comparison of mini-eUPS and TSI SMPS}

Four examples are provided herein to demonstrate the overall performance of the prototype mini-eUPS by comparing the mini-eUPS data with those measured by the Scanning Mobility Particle Sizer (SMPS; TSI Inc.). The TSI SMPS used in this comparison consisted of a particle neutralizer (i.e., either the $\mathrm{Kr}^{85}$ or soft X-ray neutralizer), a long Differential Mobility Analyzer (DMA; Model 3081, TSI Inc.) with the DMA platform (Model 3080, TSI Inc.) and UCPC (Model 3776, TSI Inc.). The SMPS was operated at the aerosol-to-sheath flow rate ratio of 1:10. All the raw SMPS data were measured in the highest resolution offered by the SMPS. Since the mini-eUPS has fewer sizing bins than TSI SMPS, the raw size bins of SMPS data were merged to the number of size bins equivalent to mini-eUPS's for the comparison.

Sub-micrometer particles in both unimodal and bimodal size distributions were generated in the lab for this part of testing. The detail of experimental setup used to generate test particles could be found in the Supplementary Information (SI; Fig. S1). Particles in unimodal size distribution were generated via the nebulization of $\mathrm{NaCl}$ solutions in $0.1 \%$ concentration by a custom-made Collison atomizer. Once produced, the particle stream was directed through a diffusion dryer with silica gel as the descendant to remove the water vapor and a $\mathrm{Po}^{210}$ neutralizer to minimize the electrical charge level on resultant particles. Particles in the bimodal size distribution were generated by mixing the unimodal $\mathrm{NaCl}$ particles produced above with diethylhexyl sebacate (DEHS) oil particles produced by a Condensation Monodisperse Aerosol Generator (Model 3475, TSI Inc.).

The comparison of size distributions measured by mini-eUPS and TSI SMPS for lab-generated particles in unimodal and bimodal distributions is shown in Fig. 6 (Fig. 6(a) for unimodal size distribution; Fig. 6(b) for the

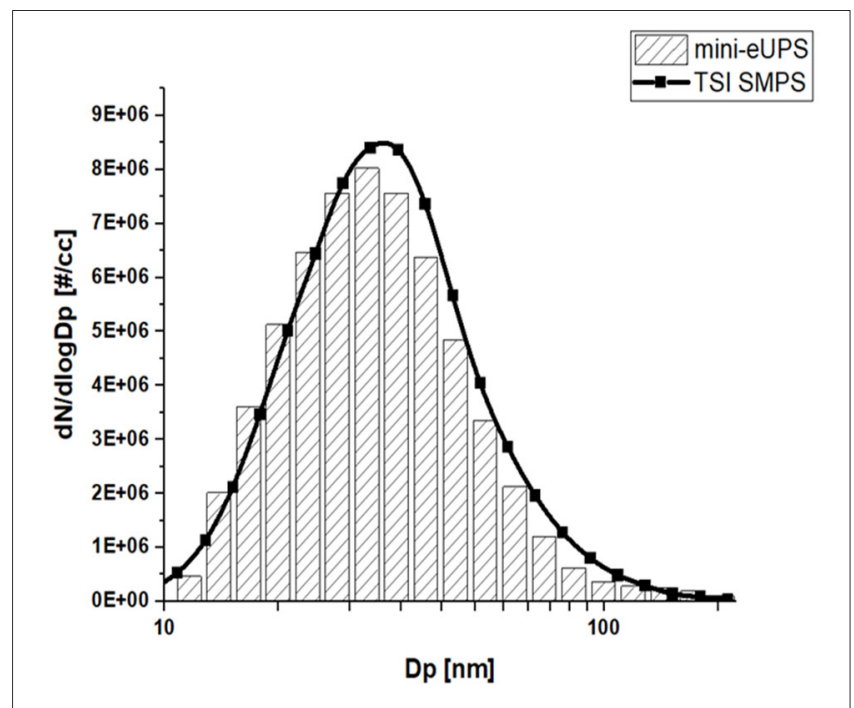

(a)

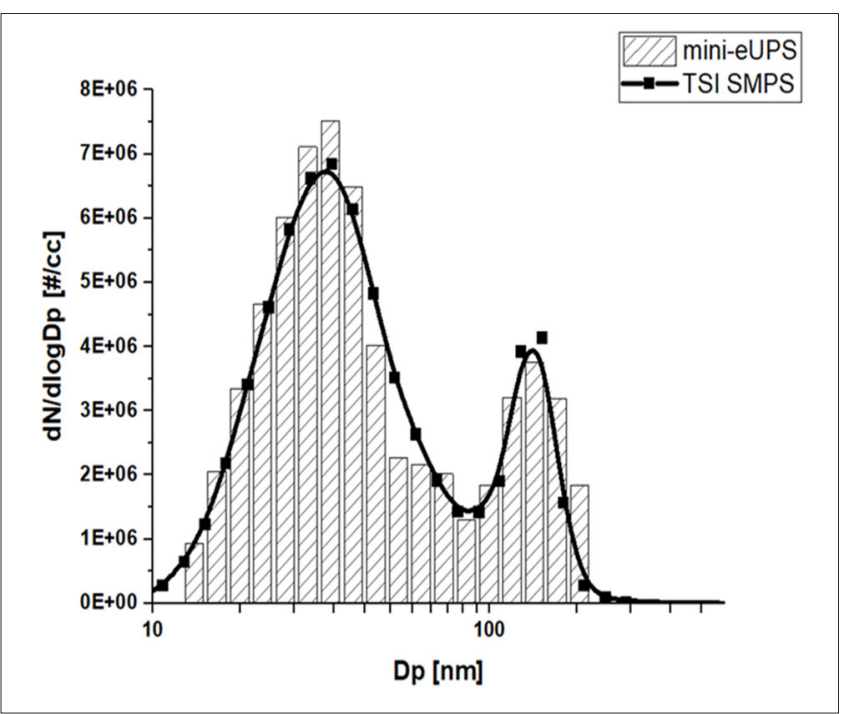

(b)

Fig. 6. Comparison of size distributions of lab-generated particles measured by TSI SMPS and mini-eUPS: (a) for unimodal size distribution; (b) for bimodal size distribution). 
bimodal size distribution). For each particle size distribution measurement, at least five runs were taken and the average of measured distributions was reported. The particle size distributions measured by mini-eUPS is in reasonable agreement with those obtained by TSI SMPS, indicating that the assembled mini-eUPS is in the working condition. The slight variation in each size bin of measured particle size distributions are primarily because of the use of different particle concentration detectors and data reduction schemes used in mini-eUPS and TSI SMPS.

Both mini-eUPS and TSI SMPS were also applied to measure the diesel particles generated from EPA Tier 2 diesel engine ( $8 \mathrm{~kW}$, Quiet Diesel, Cummins Onan). Fig. S2 shows the facility and experimental setup for this measurement. Fig. 7 shows the size distributions of diesel particles measured by both instruments. More than three runs were taken in this measurement and the average of measured distributions was reported. The reasonable agreement between two measured particle size distributions was again obtained in this measurement.

Last example of the performance comparison between mini-eUPS and SMPS is on the measurement of particulate emission from a low-cost 3D printer (LulzBot Mini, Aleph Objects, Inc.). The schematic diagram and description of the setup for this part of the measurement is included in the SI (Fig. S3). A typical comparison of printer-emitted particle size distributions measured by both mini-eUPS and TSI SMPS is shown in Fig. 8. The data shown in Fig. 8 were the averages of five measured particle size distributions. The agreement between the two shown particle size distributions was considered reasonable although the SMPS-measured concentration of particles in the range near the peak size was slightly higher than that measured by mini-eUPS. It is again possibly due to the detector difference used in mini-eUPS and TSI SMPS.

In the future, a small-scale wireless UFP monitoring network, based on multiple mini-eUPS, will be set up for field testing of mini-eUPSs and their long-term network function.

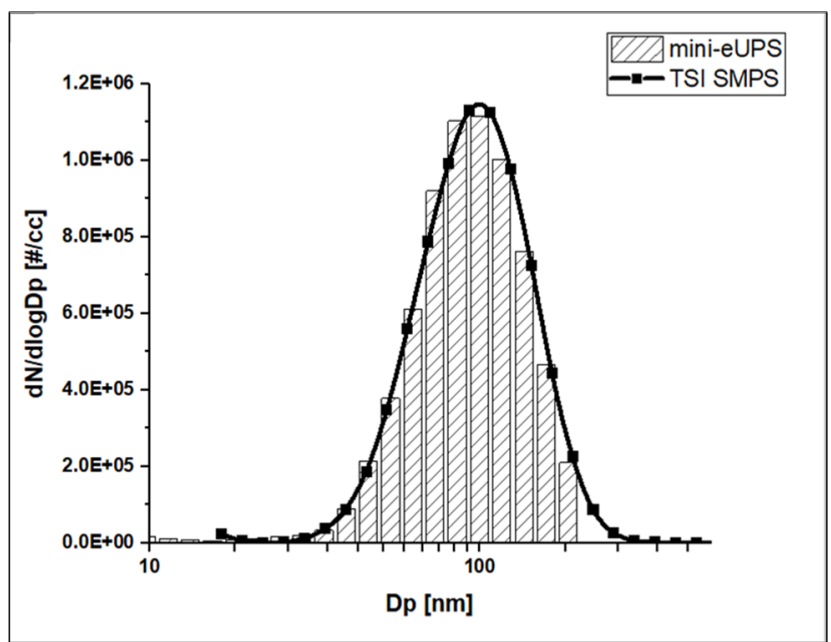

Fig. 7. Comparison of size distributions of diesel particles measured by mini-eUPS and SMPS.

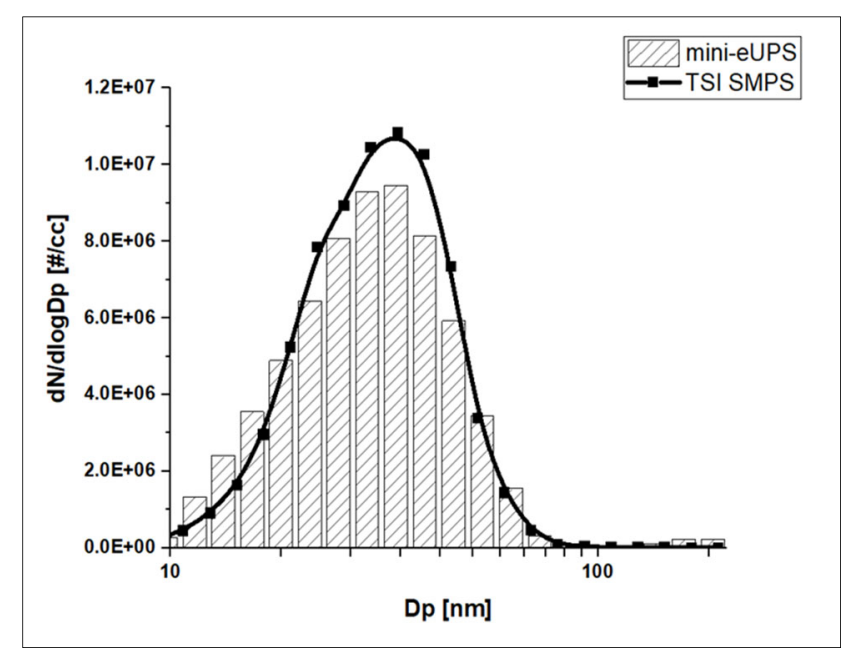

Fig. 8. Comparison of size distributions of particles emitted from a low-cost 3D printer operated at the extrusion mode (measured by mini-eUPS and SMPS).

\section{ACKNOWLEDGEMENT}

The authors, Q. Liu, D. Liu and D.R. Chen, are grateful for the partial financial support provided by the STAR program, U.S. EPA (Grant \#83513201). The authors would also like to thank Dr. Jhy-Charm Soo in CDC NIOSH (Morgantown, WV) for his help in the measurement of diesel particles.

\section{COI STATEMENT}

Chen, one of the authors, holds the licensed IP, which is similar in name, but unrelated in configuration, to this project.

\section{SUPPLEMENTARY MATERIAL}

Supplementary data associated with this article can be found in the online version at http://www.aaqr.org.

\section{REFERENCES}

Aguilera, I., Dratva, J., Caviezel, S., Burdet, L., de Groot, E., Ducret-Stich, R.E., Eeftens, M., Keidel, D., Meier, R., Perez, L., Rothe, T., Schaffner, E., Schmit-Trucksass, A., Tsai, M.Y., Schindler, C., Kunzli, N. and ProbstHensch, N. (2016). Particulate matter and subclinical atherosclerosis: Associations between different particle sizes and sources with carotid intima-media thickness in the SAPALDIA study. Environ. Health Perspect. 124: 1700-1706.

Baldauf, W.R., Devlin, B.R., Gehr, P., Giannelli, R., Hassett-Sipple, B., Jung, H., Martini, G., McDonald, J., Sacks, D.J. and Walker, K. (2016). Ultrafine particle metrics and research considerations: Review of the 2015 UFP workshop. Int. J. Environ. Res. Public Health 13: 1054.

Chen, D.R. and Pui, D.Y.H. (2008). Nanoparticle and 
ultrafine aerosol measurement. In Air sampling instruments for evaluation of atmospheric contamination, 10th Ed., ACGIH, Cincinnati, OH.

Chen, X., Liu, Q., Jiang, J. and Chen, D.R. (2018). Performance of small plate and tube unipolar particle chargers at low corona current. Aerosol Air Qual. Res. 18: 2005-2013.

Delfino, R.J., Sioutas, C. and Malik, S. (2005). Potential role of ultrafine particles in associations between airborne particle mass and cardiovascular health. Environ. Health Perspect. 113: 934-946.

Dirks, K.N., Wang, J.Y.T., Khan, A. and Rushton, C. (2016). Air pollution exposure in relation to the commute to school: A Bradford UK case study. Int. J. Environ. Res. Public Health 13: 1064.

Du, Y., Xu, X., Chu, M., Guo, Y. and Wang, J. (2016). Air particulate matter and cardiovascular disease: The epidemiological, biomedical and clinical evidence. $J$. Thorac. Dis. 8: E8-E19.

Dubey, P. and Dhaniyala, S. (2013). Improved inversion of scanning electrical mobility spectrometer data using a new multiscale expectation maximization algorithm. Aerosol Sci. Technol. 47: 69-80.

Heinlaan, M., Ivask, A., Blinova, I., Dobourguier, H.C. and Kahru, A. (2008). Toxicity of nanosized and bulk $\mathrm{ZnO}, \mathrm{CuO}$ and $\mathrm{TiO}_{2}$ to bacteria Vibrio fischeri and crustaceans Daphnia magna and Thamnocephalus platyurus. Chemosphere 71: 1308-1316.

Heusinkveld, H.J., Wahle, T., Campbell, A., Westerink, R.H.S., Tran, L., Johnston, H., Stone, V., Cassee, F.R. and Schins, R.P.F. (2016). Neurodegenerative and neurological disorders by small inhaled particles. Neurotoxicology 56: 94-106.

Hoek, G., Boogaard, H., Knol, A., de Hartog, J., Slottje, P., Ayres, J.G., Borm, P., Brunekreef, B., Donaldson, K., Forastiere, F., Holgate, S., Kreyling, W.G., Nemery, B., Pekkanen, J., Stone, V., Wichmann, H.E. and van der Sluijs, J. (2010). Concentration response functions for ultrafine particles and all-cause mortality and hospital admissions: Results of a European expert panel elicitation. Environ. Sci. Technol. 44: 476-482.

Holguin, F. (2008) Traffic, outdoor air pollution, and asthma. Immunol. Allergy Clin. North Am. 28: 577-588.

Hsiao, T.C., Chen, D.R. and Son, S.Y. (2009). Development of mini-cyclones as the size-selective inlet of miniature particle detectors. J. Aerosol Sci. 40: 481-491.

Hudda, N., Simon, M.C., Zamore, W. and Durant, J.L. (2018). Aviation-Related impacts on ultrafine particle number concentrations outside and inside residences near an airport. Environ. Sci. Technol. 52: 1765-1772.

Kandlikar, M. and Ramachandran, G. (1999). Inverse methods for analysing aerosol spectrometer measurements: A critical review. J. Aerosol Sci. 30: 413-437.

Karner, A.A., Eisinger, D.S. and Niemeier, D.A. (2010). Near-roadway air quality: Synthesizing the findings from real-world data. Environ. Sci. Technol. 44: 53345344.

Kreyling, W.G., Semmler, M., Erbe, F., Mayer, P., Takenaka, S., Schulz, H., Oberdörster, G. and Ziesenis,
A. (2002). Translocation of ultrafine insoluble iridium particles from lung epithelium to extrapulmonary organs is size dependent but very low. J. Toxicol. Environ. Health A 166: 998-1004.

Kulmala, M., Vehkamäki, H., Petäjä, T., Dal Maso, M., Lauri, A., Kerminen, V.M., Birmili, W. and McMurry, P.H. (2004). Formation and growth rates of ultrafine atmospheric particles: A review of observations. $J$. Aerosol Sci. 35: 143-176.

Lee, Y.H., Park, H.K., Lee, Y.M., Kim, K. and Park, S.B. (2007). A practical procedure for producing silver nanocoated fabric and its antibacterial evaluation for biomedical applications. Chem. Commun. 2007: 29592961.

Li, Y., Lane, J.K., Corlin, L., Patton, P.A., Durant, L.J., Thanikachalam, M., Woodin, M., Wang, M. and Brugge, D. (2017). Association of long-term near-highway exposure to ultrafine particles with cardiovascular diseases, diabetes and hypertension. Int. J. Environ. Res. Public Health 14: 461.

Liu, D., Hsiao, T.C. and Chen, D.R. (2015). Performance study of a miniature quadru-inlet cyclone. J. Aerosol Sci. 90: 161-168.

Liu, Q. (2015). Ultrafine particle generation and measurement. PhD Dissertation, Virginia Commonwealth University.

Liu, Q. and Chen, D.R. (2016). Experimental evaluation of miniature plate DMAs (mini-plate DMAs) for future ultrafine particle (UFP) sensor network. Aerosol Sci. Technol. 50: 297-307.

Madani, S.Y., Naderi, N., Dissanayake, O., Tan, A. and Seifalian, A.M. (2011). A new era of cancer treatment: Carbon nanotubes as drug delivery tools. Int. $J$. Nanomed. 6: 2963-2979.

Manigrasso, M., Natale, C., Vitali, M., Protano, C. and Avino, P. (2017). Pedestrians in traffic environments: Ultrafine particle respiratory doses. Int. J. Environ. Res. Public Health 14: 288.

Markowski, G.R. (1987). Improving Twomey's algorithm for inversion of aerosol measurement data. Aerosol Sci. Technol. 7: 127-141.

Mazaheri, M., Clifford, S., Jayaratne, R., Megat Mokhtar, M.A., Fuoco, F., Buonanno, G. and Morawska, L. (2014). School children's personal exposure to ultrafine particles in the urban environment. Environ. Sci. Technol. 48: 113-120.

Nel, A., Xia, T., Madler, L. and Li, N. (2006). Toxic potential of materials at the nanolevel. Science 311: 622-627.

Oberdörster, G., Sharp, Z., Atudorei, V., Elder, A., Gelein, R., Kreyling, W. and Cox, C. (2004). Translocation of inhaled ultrafine particles to the brain. Inhalation Toxicol. 16: 437-45.

Ostro, B., Hu, J., Goldberg, D., Reynolds, P., Hertz, A., Bernstein, L. and Kleeman, M.J. (2015). Associations of mortality with long-term exposures to fine and ultrafine particles, species and sources: Results from the California Teachers Study Cohort. Environ. Health Perspect. 123: 549-556. 
Padró-Martínez, L.T., Patton, A.P., Trull, J.B., Zamore, W., Brugge, D. and Durant, J.L. (2012). Mobile monitoring of particle number concentration and other traffic-related air pollutants in a near-highway neighborhood over the course of a year. Atmos. Environ. 61: 253-264.

Park, M.V., Neigh, A.M., Vermeulen, J.P., de la Fonteyne, L.J., Verharen, H.W., Briede, J.J., van Loveren, H. and de Jong, W.H. (2011). The effect of particle size on the cytotoxicity, inflammation, developmental toxicity and genotoxicity of silver nanoparticles. Biomaterials 32: 9810-9817.

Patel, M.M. and Miller, R.L. (2009). Air pollution and childhood asthma: Recent advances and future directions. Curr. Opin. Pediatr. 21: 235-242.

Patton, A.P., Perkins, J., Zamore, W., Levy, J.I., Brugge, D. and Durant, J.L. (2014). Spatial and temporal differences in traffic-related air pollution in three urban neighborhoods near an interstate highway. Atmos. Environ. 99: 309-321.

Paur, H., Cassee, F.R., Teeguarden, J., Fissan, H., Diabate, S., Aufderheide, M., Kreyling, W.G., Hänninen, O., Kasper, G., Riediker, M., Rothen-Rutishauser, B. and Schmid, O. (2001). In-vitro cell exposure studies for the assessment of nanoparticle toxicity in the lung-A dialog between aerosol science and biology. J. Aerosol Sci. 42: 668-692.

Philips, D.L. (1962). A technique for the numerical solution of certain integral equations of the first kind. $J$. Assoc. Comput. Mach. 9: 84-97.

Rizzi, R., Guzzi, R. and Legnani, R. (1982). Aerosol size spectra from spectral extinction data: The use of a linear inversion method. Appl. Opt. 21: 1578-1587.

Salam, M.T., Islam, T. and Gilliland, F.D. (2008). Recent evidence for adverse effects of residential proximity to traffic sources on asthma. Curr. Opin. Pulm. Med. 14: 3-8.

Samet, J.M., Dominici, F., Curriero, F.C., Coursac, I. and Zeger, S.L. (2000). Fine particulate air pollution and mortality in 20 US cities, 1987-1994. N. Engl. J. Med. 343: 1742-1749.

Samet, J.M., Graff, D., Berntsen, J., Ghio, A.J., Huang, Y.C.T. and Devlin, R.B. (2007). A comparison of studies on the effects of controlled exposure to fine, coarse and ultrafine ambient particulate matter from a single location. Inhalation Toxicol. 19: 29-32.

Smijs, T.G. and Pavel, S. (2011). Titanium dioxide and zinc oxide nanoparticles in sunscreens: Focus on their safety and effectiveness. Nanotechnol. Sci. Appl. 4: 95112.

Somasundaran, P., Fang, X., Ponnurangam, S. and Li, B. (2010). Nanoparticles: Characteristics, mechanisms and modulation of biotoxicity. Kona Powder Part. J. 28: 38 48

Stewart, J., Chalupa, D.C., Devlin, R., Frasier, L.M., Huang, L.S., Little, E.L., Lee, S.M., Phipps, R.P., Pietropaoli, A.P., Taubman, M.B., Utell, M.J. and Frampton, M.W. (2010). Vascular effects of ultrafine particles in persons with type 2 Diabetes. Environ. Health Perspect. 118: 1692-1698.

Takenaka, S., Karg, E., Roth, C., Schulz, H., Ziesenis, A. and Heinzamann U. (2001). Pulmonary and systemic distribution of inhaled ultrafine silver particles in rats. Environ. Health Perspect. 109: 547-551.

Talukdar, S.S. and Swihart, M.T. (2003). An improved data inversion program for obtaining aerosol size distributions from scanning differential mobility analyzer data. Aerosol Sci. Technol. 37: 145-161.

Twomey, S. (1965). The application of numerical filtering to the solution of integral equations encountered in indirect sensing measurements. J. Franklin Inst. 279: 95-109.

Twomey, S. (1975). Comparison of constrained linear inversion and an iterative nonlinear algorithm applied to the indirect estimation of particle size distributions. $J$. Comput. Phys. 18:188-200.

United States Environmental Protection Agency (U.S. EPA) (2009). Integrated Science Assessment for Particulate Matter: Final Report; EPA/600/6-08/139F; National Center for Environmental Assessment, Office of Research and Development: Research Triangle Park, NC, USA.

Vassiliou, A., Bikiaris, D., Chrissafis, K., Paraskevopoulos, K.M., Stavrev, S.Y. and Docoslis, A. (2008). Nanocomposites of isotactic polypropylene with carbon nanoparticles exhibiting enhanced stiffness, thermal stablitiy and gas barrier properties. Compos. Sci. Technol. 68: 933-943.

Voutilainen, V., Stratmann, F. and Kaipio, J.P. (2000). A non-homogenous regularization method for the estimation of narrow aerosol size distribution. J. Aerosol Sci. 31: 1433-1445.

Wolfenbarger J.K. and Seinfeld, J.H. (1999). Inversion of aerosol size distribution Data. J. Aerosol Sci. 21: $227-$ 247

Zhu, Y., Hinds, W.C., Kim, S., Shen, S. and Sioutas, C. (2002). Study of ultrafine particles near a major highway with heavy-duty diesel traffic. Atmos. Environ. 36: 4323-4335.

Received for review, November 26, 2018 Revised, February 27, 2019 Accepted, March 10, 2019 